\title{
EFEKTIVITAS LABORATORIUM VIRTUAL SEBAGAI MEDIA PEMBELAJARAN PADA EKSPERIMEN VISKOSITAS
}

\author{
Vebrina Bunga Langngan, Djeli Alvi Tulandi, Theresje Mandang \\ Fakultas Matematika dan Ilmu Pengetahuan Alam, Universitas Negeri Manado \\ email: djelitulandi@unima.ac.id
}

\begin{abstract}
ABSTRAK
Terbatasnya peralatan laboratorium serta adanya pandemi Covid-19 saat ini menjadi penyebab kegiatan praktikum tidak berjalan dengan optimal. Untuk mengatasi kendala tersebut maka laboratorium virtual dapat digunakan sebagai media pembelajaran jarak jauh. Penelitian ini bertujuan untuk mengetahui efektivitas penggunaan laboratorium virtual sebagai media pembelajaran pada eksperimen viskositas. Penelitian ini adalah penelitian pre-eksperimen dengan desain one group pretest-posttest design. Subjek penelitiannya adalah mahasiswa semester I Jurusan Fisika Universitas Negeri Manado 2020/2021. Pengambilan data mengggunakan tes dengan instrument tes dalam bentuk essay dan keterampilan proses sains serta penilaian afektif menggunakan rubrik. Rata-rata hasil pretest 43,75 dan hasil posttest 84,38 . Rata-rata hasil penilaian keterampilan proses sains berada pada kriteria baik (66\%-79\%) dan kriteria sangat baik (80\%$100 \%)$ sedangkan penilaian afektif berada pada kriteria sangat baik (80\%-100\%). Perolehan nilai $\mathrm{N}$-gain dari masing-masing mahasiswa, terdapat sebanyak 10 mahasiswa pada kategori N-Gain tinggi dengan persentase $62,5 \%$ dan sebanyak 6 mahasiswa berada pada kategori $\mathrm{N}$-Gain sedang dengan persentase $37,5,0 \%$. Hasil persentase rata-rata N-Gain dari 16 mahasiswa adalah 74,9\%. Hasil penelitian ini menunjukkan bahwa penggunaan laboratorium virtual cukup efektif digunakan sebagai media pembelajaran pada eksperimen viskositas.
\end{abstract}

Kata kunci : Efektivitas, Laboratorium Virtual, Media Pembelajaran

\begin{abstract}
Limited laboratory equipment and the current pandemic Covid-19 are the causes of practicum activities not running optimally.to overcome these obstacles, the virtual laboratory can be used as a medium for distance learning. This study aims to determine the effectiveness of using virtttual laboratories as learning media in viscosity experiments. This research is a pre-experimental study with one group pretest-posttest design. The research subjects were semester I Students of the Departement of Physics, Manado State University 2020/2021. Retrieval of data using test instruments in the form of essays and science process skills and affective using rubrics. The average preest results were 43,75 and posttest results were 84,38. The average results of the assessment of science process skills are in good criteria (66\%-79\%) and very good criteria (80\%-100\%) while affective assessments are very good criteria (80\%-100\%). For each student, there were 10 students in high $\mathrm{N}$-Gain category with a percentage of $62,5 \%$ and 6 students in the moderate $\mathrm{N}$-Gain category with a percentage of $37,5 \%$. The results of the average $N$-Gain percentage of 16 students was $74,9 \%$. The results of this study indicate that use of a virtual laboratory is quite effective in being used as a learning medium in viscosity experiments.
\end{abstract}

Keywords $\quad$ : Effectiveness, Virtual Laboratory, Learning Media 


\section{PENDAHULUAN}

Fisika merupakan cabang dari ilmu pengetahuan alam yang sangat berperan penting dalam bidang ilmu pengetahuan dan IPTEK karena mempelajari mengenai fenomena alam dan bentuk materi dalam ruang dan waktu. Dalam pengembangan ilmu pengetahuan dan teknologi diperlukan penguasaan dan pemahaman konsep-konsep fisika pada umumnya. Penguasaan konsep fisika, baik mengenai fenomena alam maupun masalah yang dihadapi, dapat dipahami, dianalisis, dan diinterprestasikan dengan benar sehingga informasi mengenai penyelesaian dari suatu permasalahan dapat dibenarkan secara ilmiah (Pujayanto, dkk., 2017).

Mempelajari fenomena atau gejala alam, fisika menggunakan proses dimulai dari pengamatan, pengukuran, analisis dan menarik kesimpulan, sehingga proses yang dibutuhkan tergolong cukup panjang, namun hasilnya bisa dipastikan akurat karena fisika termasuk ilmu eksak yang kebenarannya terbukti. Kebenaranya dapat dibuktikan dalam kegiatan praktikum (Yohan, 2020). Kegiatan praktikum dapat memberi pengalaman langsung dan melibatkan peserta didik secara aktif sehingga dapat menunjang proses pembelajaran fisika (Hidayanti, dkk., 2019). Kegiatan praktikum akan memberikan peran yang sangat besar dalam membangun pemahaman konsep, verifikasi kebenaran konsep, menumbuhkan keterampilan, proses serta keefektifan peserta didik, menumbuhkan motivasi pelajaran dan melatih kemampuan psikomotor (Sutrisno dalam Yuanita, dkk., 2015). Menurut Trianto dalam Mondolang dan Asmarianto (2015) materi pembelajaran akan mudah dipelajari, dipahami, dihayati, dan diingat dalam waku yang relative lama apabila peseta didik memperoleh pengalaman langsung dari peristiwa belajar melalui pengamatan atau eksperimen.

Terbatasnya peralatan dan sarana untuk praktek laboratorium serta keterbatasan waktu menjadi salah satu penyebab praktikum sulit untuk dilaksanakan. Terlebih pada masa pandemi saat ini, kegiatan praktikum fisika menjadi terkendala, mengingat peserta didik tidak dapat mengakses laboratorium riil yang ada di sekolah/kampus. Sehingga perlu adanya suatu media pembelajaran jarak jauh yang dapat menjangkau peserta didik agar dapat melaksanakan kegiatan prakikum secara mandiri.

Keterlibatan penggunaan Teknologi Komunikasi dan Informasi menjadi sangat penting untuk mengatasi kendala pelaksanaan praktikum. Perkembangan teknologi informasi dan komunikasi menyediakan kesempatan untuk menciptakan inovasi-iovasi khususnya dalam pembelajaran fisika dengan memanfaatkan internet maupun penggunaan computer sehingga pembelajaran dapat dilaksanakan kapanpun dan dimanapun (Tulandi \& Wejasu, 2019). Salah satunya dengan menggunakan pembelajaran multimedia dalam bentuk laboratorium virtual/E- Praktikum.

Laboratorium virtual adalah paket simulasi perangkat lunak yang mensimulasikan proses laboratorium (Okoyeigbo, dkk., 2020). Laboratorium virtual dapat didefiniskan sebagai program computer yang memungkinkan siswa untuk menjalankan simulasi melalui web (Ranjan, 2017). Laboratorium virtual cukup relevan untuk diimplementasikan menjadi solusi keterbatasan sumber daya pembelajaran serta menjadi media yang cukup efektif, mengingat fungsinya yang bisa dikerjakan parallel baik sebagai praktikan maupun dari sisi laboratorium (Kusumaningsih, dkk., 2014). Peserta didik dapat melaksanakan eksperimen dimanapun dan kapanpun mereka butuhkan, siswa dapat melakukan lebih banyak pengalaman simulasi dan dapat memperoleh lebih banyak informasi untuk memperoleh gmbaran keseluruhaan dari kegiatan praktikum tersebut (Domínguez, dkk.,2018).

Laboratorium virtual bukanlah pengganti laboratorium riil tetapi digunakan untuk melengkapi dan memperbaiki kelemahankelemahan yang ada (Fatik \& Madzalim, 2012). Laboratorium virtual dapat digunakan sebagai alat pendukung di laboratorium nyata atau sebagai alternative apabila peralatan laboratorium nyata terbatas (Tatli \& Ayas, 2010). Dengan adanya laboratorium virtual, diharapkan mampu mengatasi masalah kegiatan praktikum agar dapat berjalan dengan optimal khususnya pada masa pandemi covid 19 saat ini.

\section{METODE PENELITIAN}

Penelitian dilaksanakan di Jurusan Fisika secara online dengan menggunakan zoom meeting pada mahasiswa Jurusan Fisika Universitas Negeri Manado semester I kelas B 
pada bulan Desember 2020. Dalam penelitian ini populasinya adalah mahasiswa semester I Jurusan Fisika. Penarikan sampel menggunakan simple random sampling dan dilibatkan satu kelas yaitu mahasiswa Jurusan Fisika kelas B Semester I.

Penelitian ini menggunakan dua variabel, yakni Variabel independen (Variabel Bebas) adalah laboratorium virtual sebagai media pembelajaran. Variabel dependen (Variabel Terikat) adalah hasil belajar (Posttest), keterampilan proses sains, dan sikap.

Penelitian ini menggunakan metode preeksperimen dengan desain penelitian OneGroup Pretest-Posttest Design. Penelitian ini tidak menggunakan kelas pembanding namun sebelum di berikan perlakuan di berikan tes awal atau pretest. Dengan demikian hasil perlakuan dapat di ketahui lebih akurat, karena dapat membandingkan dengan keadaan sebelum di berikan perlakuan (Sugiyono,2018). Desain ini dapat digambarkan sebagai berikut:

Tabel 1. Rancangan Penelitian

\begin{tabular}{cccc}
\hline Kelompok & Pretest & Treatment & Posttest \\
\hline Kelas B & $\mathrm{O}_{1}$ & $\mathrm{X}$ & $\mathrm{O}_{2}$ \\
\hline
\end{tabular}

Dalam penelitian ini instrument yang digunakan berupa tes (pretest dan posttest) dalam bentuk essay, penilaian keterampilan proses sains dan penilaian afektif.

Teknik analisis data menggunakan analisis uji N-Gain sebagai ukuran dari efektivitas laboratorium virtual sebagai media pembelajaran pada eksperimen viskositas yang telah menjadi ukuran standar dalam melaporkan skor pada konsep berbasis penelitian. Rumus untuk menentukan N-Gain menurut Meltzer dalam Gunawan, dkk (2017) dengan skor maksimum 100 adalah sebagai berikut:

$$
\mathrm{N}-\text { Gain }=\frac{\text { Skor posttest }- \text { skor pretest }}{\text { Skor ideal }- \text { skor pretest }}
$$

Interpretasi N-Gain menurut Hake dalam Nazir dan Sari (2019) disajikan dalam tabel sebagai berikut:

Tabel 2. Klasifikasi Interprestrasi N-Gain

\begin{tabular}{cl}
\hline Interval & Kategori \\
\hline$g>0,7$ & Tinggi \\
\hline $0,3 \leq g \leq 0,7$ & Sedang \\
\hline$g<0,3$ & Rendah \\
\hline
\end{tabular}

\section{HASIL DAN PEMBAHASAN}

\section{Hasil Penelitian}

Secara keseluruhan kegiatan penelitian ini dilakukan dengan tiga tahap. Tahap pertama yaitu memberikan pretest untuk mengetahui kemampuan awal mahasiswa, tahap kedua memberikan perlakuan menggunakan simulasi laboratorium virtual yang dikembangkan oleh Universitas di India, Amrita Vishwa Vidyapeetham dan CDAC Mumbai dalam bentuk web/link dalam eksperimen viskositas. Setelah diberi perlakuan maka langkah ketiga adalah melakukan tes akhir. Tes akhir yaitu memberikan posttest untuk mengetahui keefektifan penggunaan laboratorium virtual terhadap eksperimen viskositas.

Hasil penelitian diperoleh data analisis statistik hasil pretest dan posttest sebagai berikut:

\begin{tabular}{lr}
\multicolumn{2}{c}{ Tabel 3. Tabel hasil Pretest } \\
\hline Statistik & Pretest \\
\hline $\mathrm{N}$ & 16 \\
\hline Mean & 43,75 \\
\hline Std. Deviation & 10,72 \\
\hline Minimum & 25 \\
\hline Maximum & 65 \\
\hline Variance & 115 \\
\hline \% jumlah mahasiswa memperoleh nilai di \\
atas nilai mean
\end{tabular}

\section{Tabel 4. Hasil Posttest}

\begin{tabular}{lr}
\hline Statistik & Posttest \\
\hline $\mathrm{N}$ & 16 \\
\hline Mean & 84,38 \\
\hline Std. Deviation & 7,04 \\
\hline Minimum & 75 \\
\hline Maximum & 95 \\
\hline Variance & 44,04 \\
\hline $\begin{array}{l}\text { \% jumlah mahasiswa memperoleh nilai di } \\
\text { atas nilai mean }\end{array}$ & 62,5 \\
\hline $\begin{array}{l}\text { \% jumlah mahasiswa memperoleh nilai di } \\
\text { bawah nilai mean }\end{array}$ & 37,5 \\
\hline
\end{tabular}

Pada tabel 2 di atas menunjukan nilai ratarata pretest adalah 43,75 dengan nilai minimum 25 dan nilai maksimum 65 . Mahasiswa memperoleh nilai di atas nilai mean memiliki persentase $56,3 \%$, sedangkan mahasiswa memperoleh nilai di bawah nilai mean memiliki persentase 43,8\%. Sedangkan pada tabel 3 menunjunjukkan nilai rata-rata posttest adalah 84,38 dengan nilai minimum 75 dan nilai maksimum 95. Mahasiswa memperoleh nilai di atas nilai mean memiliki 
persentase 62,5 sedangkan mahasiswa memperoleh nilai di bawah nilai mean memiliki persenase $37,5 \%$.

Tabel 5. Hasil Keterampilan Proses Sains LKPD

\begin{tabular}{clc}
\hline No & \multicolumn{1}{c}{ Indikator } & $\begin{array}{c}\text { Persentase } \\
\text { Penilaian }\end{array}$ \\
\hline 1 & $\begin{array}{l}\text { Mengidentifikasi } \\
\text { Variabel }\end{array}$ & $75 \%$ \\
\hline 2 & Merumusan Hipotesis & $78 \%$ \\
\hline 3 & Melakukan Eksperimen & $83 \%$ \\
\hline 4 & Menginterprestasi Data & $86 \%$ \\
\hline 5 & Menganalisis & $83 \%$ \\
\hline 6 & Menyimpulkan & $80 \%$ \\
\hline 7 & Mengkomunikasikan & $84 \%$ \\
\hline
\end{tabular}

Dari tabel 5 menunjukkan hasil penilaian keterampilan proses sains dari LKPD, pada ketujuh indikator perolehan persentase penilaian berada pada kriteria baik (66\%-79\%) dan kriteria sangat baik (80\%-100\%). Adapun hasil rata-rata yang diperoleh pada indikator mengidentifikasi variabel $76 \%$, merumuskan hipotesis $78 \%$, melakukan eksperimen $83 \%$, mengintepretasi data $86 \%$, menganalisis $83 \%$, menyimpulkan $80 \%$ dan mengkomunikasikan diperoleh rata-rata $84 \%$.

Tabel 6. Hasil Penilaian Afektif

\begin{tabular}{rlc}
\hline No & \multicolumn{1}{c}{ Indikator } & $\begin{array}{c}\text { Persentase } \\
\text { Penilaian }\end{array}$ \\
\hline 1 & Rasa Ingin Tahu & $81 \%$ \\
\hline 2 & Disiplin & $86 \%$ \\
\hline 3 & Tanggung Jawab & $88 \%$ \\
\hline 4 & Kritis & $84 \%$ \\
\hline
\end{tabular}

Dari tabel 6 menunjukkan skor perolehan mahasiswa berdasarkan penilaian sikap pada LKPD. Adapun hasil yang diperoleh adalah untuk indicator rasa ingin tahu diperoleh persentase penilaian $81 \%$, disiplin $86 \%$, tanggung jawab $88 \%$, dan kritis $84 \%$. Keempat indicator tersebut berada dalam kategori sangat baik (80\%-100\%).

Tabel 7. Kategori Skor N-Gain

\begin{tabular}{|c|c|c|c|c|c|}
\hline & & $\begin{array}{c}\text { Freque } \\
\text { ncy }\end{array}$ & $\begin{array}{c}\text { Perc } \\
\text { ent }\end{array}$ & $\begin{array}{l}\text { Vali } \\
\text { d } \\
\text { Perc } \\
\text { ent }\end{array}$ & $\begin{array}{c}\text { Cumula } \\
\text { tive } \\
\text { Percent }\end{array}$ \\
\hline $\begin{array}{l}\text { Val } \\
\text { id }\end{array}$ & $\begin{array}{c}\text { Ting } \\
\text { gi }\end{array}$ & 10 & 62.5 & 62.5 & 62.5 \\
\hline & $\begin{array}{c}\text { Seda } \\
\text { ng }\end{array}$ & 6 & 37.5 & 37.5 & 100.0 \\
\hline & $\begin{array}{c}\text { Tota } \\
1 \\
\end{array}$ & 16 & $\begin{array}{c}100 . \\
0\end{array}$ & $\begin{array}{c}100 . \\
0\end{array}$ & \\
\hline
\end{tabular}

Berdasarkan tabel 6, hasil perhitungan skor N-Gain menunjukkan terdapat 10 mahasiswa berada pada kategori tinggi dengan persentase $62,5 \%$ dan 6 mahasiswa berada pada kategori sedang dengan persentase 37,5

Tabel 7. Persentase Perolehan skor N-Gain

\begin{tabular}{lrr}
\hline \multicolumn{3}{c}{ Statistics } \\
\hline \multicolumn{3}{c}{ Persentase N Gain } \\
\hline $\mathrm{N}$ & Valid & 16 \\
\hline \multicolumn{3}{c}{ Missing } \\
\hline Mean & 0 \\
\hline Minimum & 749.999 \\
\hline Maximum & 54.55 \\
\hline
\end{tabular}

Dari tabel 7, menunjukan hasil perolehan rata-rata skor $\mathrm{N}$-Gain dari 16 mahasiswa diperoleh skor sebesar 74,9\%. Skor tersebut berada pada kisaran antara 56-75 dengan kategori cukup efektif sehingga dapat disimpulkan bahwa laboratorium virtual cukup efektif digunakan sebagai media pembelajaran pada eksperimen viskositas.

\section{Pembahasan}

Berdasarkan analisis data penelitian yang dilakukan pada mahasiswa semester I Jurusan Fisika Universitas Manado melalui virtual dengan menggunakan zoom meeting sesuai dengan waktu yang telah ditentukan. Hasil penelitian menunjukkan bahwa terdapat perbandingan rata-rata hasil pretest dan posttest. Sebelum diberikan perlakuan, kemampuan awal mahasiswa diukur dengan menggunakan pretest dengan rata-rata hasil pretest 43,75 . Sedangkan setelah diberikan perlakuan melalui kegiatan eksperimen viskositas melalui laboratorium virtual diperoleh hasil pretest sebesar 84,38. Dari hasil analisis ini dapat disimpulkan bahwa terdapat peningkatan setelah diberlakukannya laboratorium virtual sebagai media pembelajaran dalam eksperimen viskositas.

Dalam proses pengambilan data melalui penilaia keterampilan proses pada LKPD digunakan tujuh indikator yaitu mengidentifikasi variabel, merumuskan hipotesis, melakukan eksperimen, menginterpretasi data, menganalisis data, menyimpulkan dan mengkomunikasikan. Dari ketujuh indikator tersebut maka diperoleh ratarata hasil penilaian proses berada pada kategori baik (66\%-79\%) dan kategori sangat baik (80\%-100\%). Sedangkan pada hasil penilaian sikap pada LKPD diperoleh rata-rata hasil penilaian pada empat indikator berada pada kategori sangat baik (80\%-100\%).

Keefektifan penggunaan laboratorium virtual sebagai media pembelajaran diuji dengan menggunakan uji N-Gain. Dari hasil analisis data uji N-Gain menggunakan bantuan 
SPSS 22, perolehan nilai N-Gain dari masingmasing mahasiswa yaitu sebanyak 10 mahasiswa dengan kategori $\mathrm{N}$ - Gain tinggi dengan persentase $62,5 \%$ dan sebanyak 6 mahasiswa dengan kategori N-Gain sedang dengan persentase $37,5 \%$. Sehingga rata-rata skor N-Gain yang diperoleh dari keseluruhan mahasiswa untuk mengetahui keefektifan laboratorium virtual sebagai media pembelajaran dalam eksperimen viskositas diperoleh skor $74,9 \%$. Sesuai dengan pembagian skor N-gain, hasil tersebut termasuk dalam kisaran 56-75 dengan kategori cukup efektif. Maka dapat disimpulkan bahwa laboratorium virtual cukup efektif digunakan sebagai media pembelajaran pada eksperimen viskositas.

\section{KESIMPULAN}

Berdasarkan hasil dan pembahasan yang diperoleh, dapat disimpulkan bahwa laboratorium virtual cukup efektif digunakan sebagai media pembelajaran pada eksperimen viskositas. Dilihat dari hasil skor N-Gain terdapat 10 mahasiswa berada pada kategori tinggii dengan persentase 62,5 dan terdapat 6 mahasiswa berada pada kategori sedang dengan persentase $37,5 \%$. Sehingga rata-rata skor NGain yang diperoleh seluruh mahasiswa berada pada kategori cukup efektif dengan rata-rata $74,9 \%$.

\section{REFERENSI}

Dominguez, J. C., Miranda, R., Gonzalez, Oliet, M., \& Alonso, M. (2018). A Virtual Lab As A Complement to Trradisional Hands-On Labs: Characterization of an Alkaline Electrolyzer for Hidrogen Production. Education for Chemical Engineers, 7-17.

Fatik, Z., \& Madzalim. (2012, September). Pengembangan Perangkat Pembelajaran Fisika Dengan Virtual Lab PhET Pada Materi Gelombang Elektromagnetik Di SMAN 1 Kutorejo. Jurnal Inovasi Pendidikan Fisika, 1(1), 158-165.

Hidayanti, Masril, Darvina, Y., \& Zakiya, Z. (2019). fektivitas Lembar Kerja Siswa Virtual Laboratory pada Materi Gerak Lengkung di Kelas X SMAN. Jurnal Eksakta Pendidikan, 3(1), 47-54.

Mondolang, A. H., \& Asmarianto, I. B. (2015). Pengembangan Media Pembelajaran Digital Sistem Offline Materi Fisika
(Gelombang Bunyi). Prosiding Seminar Nasional Fisika Dan Pembelajarannya, 96-100.

Okoyeigbo, O., Agboje, E., Omuabor, E., Samson, U. A., Orimogunje, \& Abidemi. (2020, Desember). Design and Implementation of A Java Based Virtual Laboratory For Data Communication Simulation. International Journal of Electrical and Computer Engineering, 5883-5890. doi:10.11591/ijece.v10i6.pp5883-5890

Pujayanto, Supurwoko, Radiyono, Y., \& A, D. W. (2017). Development of ProblemBased Learning Material for Physics Mathematics and its Implementation. International Journal of Science and Applied Science: Coference Series, 1(1), 16-24.

Putri, Z. S. (2020). Efektivitas Pembelajaran Menggunaan Laboratorium Virtual Terhadap Kemampuan Berpikir Kritis Siswa Pada Materi Titrasi Asam Basa. [Thesis] Universias Islam Negeri Sultan Syarif Kasim Riau

Ranjani, A. (2017, Februari). Effect Of Virtual Laboratory on Development Of Concept And Skill In Physics. International Journal of Technical Research \& Science, 2(1), 1521.

Ridwan, A. R. (2018). Efektivitas Penerapan Pendekatan SAVI Setting Cooperative Script Pembelajaran Matematika Siswa Kelas IX SMP Negeri 33 Makassar. [Skripsi] Unversitas Negeri Makassar.

Simbolon, D., \& Sahyar. (2015, Desember). Pengaruh Model Pembelajaran Inkuri Terbimbing Berbasis Eksperimen Riil dan Laboratorium Virtual Terhadap Hasil Belajar Fisika Siswa. Jurnal Pendidikan dan Kebudayaan, 23(1), 299-315.

Suryanti, E., Fitriani, A., Redjeki, S., \& Riandi. (2019, Oktober). Persepsi Mahasiswa terhadap Penggunaan Virtual Laboratory dalam Pembelajaran Biologi Molekuler. Journal of Natural Scienc and Integration, 2(2), 153-162.

Tatli, S., \& Ayas, A. (2010). Virtual Laboratory Applications in Chemistry Education. Elsevier,938-942. doi:10.1016/j.sbspro.2010.12.263

Tulandi, D., \& Wejasu, C. (2019). Pengembangan Perangkat Lunak Untuk Pembelajaran Listrik Dnamis. Jurnal 
Pendidikan Fisika Tadulako, 7(3), 22-25.

Yohan, J. (2020). Pengembangan Panduan

Praktikum Generator Satu Fase Dan Tiga Fase Berbasis Inkuiri Terbimbing Dengan Mentoring.[Skripsi] Tondano: Universitas Negeri Manado.

Yuanita, D. I., Akhsan, H., \& Wiyono, K. (2015). Pengembangan Panduan Praktikum Spektroskopi Pada Mata Kuliah Modern. Jurnal Inovasi dan Pembelajaran Fisika, 2(1), 77-87 